\title{
Imágenes literarias de la ciudad santa de La Meca y de otras ciudades saudíes en la obra de Raja Alem
}

\author{
Milagros NuIN MONREAL \\ Departamento de Estudios Árabes e Islámicos \\ Universidad Complutense de Madrid \\ milagros.nuin@filol.ucm.es
}

Recibido: 18 de julio de 2011

Aceptado: 22 de septiembre de 2011

\section{Resumen}

El presente artículo se propone realizar un recorrido por distintas descripciones de la ciudad de La Meca, en el pasado, a través de la obra de algunos viajeros medievales, y en el presente, en algunas novelas de la autora saudí Raja Alem. En el repaso de estas obras se podrá comprobar de forma fehaciente cómo se ha mantenido el ambiente de la ciudad hasta finales del siglo XX, cuando, debido a un afán arquitectónico imparable de crear y destruir, el perfil de la ciudad está cambiando radicalmente y de forma irreversible. Pocas voces se han alzado en medios que no sean estrictamente privados, y una de ellas es la de la valiente escritora Raja Alem. El último apartado está dedicado a otras ciudades: Riad, Medina, Yidda...

Palabras clave: imágenes literarias, La Meca, Raja Alem, Medina, Riad.

Title: Literary Images of the Holy city of Mecca and other Saudi cities in the work of Raja Alem

\section{Abstract}

This article proposes to make a journey through different descriptions of the city of Mecca in the past, through the work of some medieval travelers, and in the present, in some novels of the female saudi writer, Raja Alem. The reviewing of these works can be a reliable way to check how it has maintained the atmosphere of the city until the late twentieth century when, due to architectural unstoppable desire to create and destroy, the skyline is changing dramatically and irreversibly. Few voices have been raised in environments that are not strictly private, and one of them is the courageous writer Raja Alem. The last section is devoted to other cities: Riyadh, Medina, Yeddah...

Keywords: literary images, Mecca, Raja Alem, Medina, Riyadh.

\section{Índice}

1. Introducción

2. Imágenes de La Meca en dos novelas de Raja Alem: Játim y Sidi Wahdana

3. Imágenes recientes de La Meca en Tawq al-Hamam

4. Imágenes de otras ciudades saudíes: Medina, Riad, Yidda

5. Conclusión 


\section{Introducción}

No son pocas las ciudades cuyo nombre está asociado al de algún escritor. Algunos ejemplos conocidos son los siguientes: Dublín y J. Joyce, El Cairo y N. Mahfuz, Alejandría y L. Durrel, los barrios periféricos de El Cairo (Embaba) e I. Aslán, etc. Mas si se trata de la ciudad de La Meca en el siglo XX y en la actualidad, es inevitable mencionar el nombre de la escritora saudí Raja Alem, originaria de dicha ciudad, con la que mantiene un fuerte vínculo afectivo y cuyo recuerdo constituye para ella una fuente de inspiración muy fértil.

La ciudad de La Meca, centro neurálgico de la religiosidad musulmana, ha sido objeto de descripción desde los siglos XI y XII hasta la actualidad. Los viajeros medievales fueron los primeros interesados en trasladar sus impresiones a los libros que componían y que estaban destinados a los futuros peregrinos a los lugares santos del islam.

No obstante, a pesar de que estas obras responden a una finalidad eminentemente religiosa, no literaria, también se pueden detectar en ellas datos relativos a imágenes que aproximan al lector al "espíritu" de la ciudad.

De este modo Nasir-i Jusraw, originario de Transoxiana, realizó la peregrinación a La Meca a mediados del siglo XI, y en el relato de viajes (Rihla) que realizó sobre sus experiencias describe con detalle los países y ciudades que visitó y el ritual de la Peregrinación. De la ciudad de La Meca ofrece unas imágenes impagables, como son las siguientes:

Al pie del monte Merwèh se encuentra un bazar con veinte locales, situados unos frente a otros, todos ellos ocupados por barberos que rasuran la cabeza a los peregrinos. Cuando la ceremonia de la umrah ha terminado, el peregrino se aleja de este valle sagrado y entra en el gran bazar, situado en la zona oriental, llamado el zoco de los Perfumistas. Este bazar está bien construido y únicamente lo ocupan perfumistas y drogueros.

En La Meca hay dos baños pavimentados con el tipo de piedras verdes que se usan para afilar los cuchillos.

Según mis cálculos no había en La Meca más de dos mil habitantes varones nacidos en la ciudad; el resto de la población se componía de quinientos extranjeros.

En esta época la escasez reinaba en la ciudad. Dieciséis men de trigo costaban un dinar magrebí y muchos de sus habitantes habían emigrado.

En La Meca se ven casas grandes destinadas a recibir a las gentes de las ciudades del Jurasán, de Iraq y de Transoxiana, entre otros países. En la época en que yo estuve allí la mayoría de estos edificios estaban en ruinas. (Nasir-i Jusraw 1999: 154) 
Otro viajero, Ibn Yubayr, andalusí nacido en Valencia y fallecido en Alejandría, también escribe, un siglo después, a mediados del siglo XII, un libro de viajes (Rihla) que sirvió como modelo de este tipo de relatos hasta comienzos del XX. Responde también a unos parámetros realistas y ofrece unas descripciones extremadamente detalladas de los lugares que visita. De los alrededores de la Gran Mezquita dice lo siguiente:

Al lado del noble santuario hay numerosas casas que tienen puertas por las que se tiene acceso a él. iCon esta noble vecindad te basta! Como la casa de Zubayda, la casa del Cadí, la llamada casa de alAyala y otras. Alrededor del santuario hay también numerosas casas que lo circundan, que tienen vistas a él y desde cuyas azoteas se tiene acceso a la azotea del santuario. Sus gentes pasan la noche en ella y enfrían el agua en lo más alto de las almenas. (Ibn Yubayr 1988: 132)

Este viajero también se hace eco del bullicio de los mercados, que tienen que cruzar los peregrinos en sus idas y venidas rituales. Estos mercados, al contrario de lo que afirmaba el viajero anterior, en el siglo XII aparecen provistos de todos los géneros imaginables, reuniendo lo mejor de Oriente y Occidente, en palabras de Ibn Yubayr. De estos datos se deduce que la situación de la ciudad había mejorado bastante en el transcurso de un siglo.

Y cuando habla de la tradición del ayuno en el mes de Ramadán y las llamadas a romperlo o reanudarlo poco antes del alba, ofrece datos indirectos sobre el urbanismo de la ciudad, como en el párrafo siguiente:

En todas las casas de La Meca hay altas azoteas; aquellos que no pueden oír el llamamiento de la comida del alba, porque su morada está lejos de la mezquita, perciben las dos lámparas que arden en lo más alto del alminar; cuando no las ven, saben que el momento de la comida ya ha pasado. (Ibn Yubayr 1988: 177-178)

Respecto a la vida social de la época en la ciudad, Ibn Yubayr relata cómo los personajes más pudientes de la ciudad organizan fiestas para los habitantes de La Meca sin distinción con motivo del mes de Ramadán y aporta descripciones valiosísimas, como son las siguientes:

Los jóvenes de La Meca ocuparon todas las almenas de la Gran Mezquita y se les puso en la mano de cada uno de ellos una bola de trapos impregnados de aceite. Ellos las colocaron encendidas en las cúspides de las almenas. Cada grupo de jóvenes tomó a su cargo uno de los cuatro lados del santuario, y cada grupo se puso a competir con los otros en su rapidez para iluminarlo. El espectador se imagina que el fuego brinca de almena en almena, porque sus siluetas se 
ocultan tras la luz que deslumbra los ojos. En el curso para realizar esto, dicen en voz alta, con una sola lengua: "iOh mi Señor! iOh mi Señor!". Entonces el santuario se estremece con sus voces. (Ibn Yubayr 1988: 185-186)

Hay otras cuestiones vinculadas al momento histórico en el que Ibn Yubayr visita La Meca, que en su relato no puede dejar de pasar por alto. Se trata de la visita del emir Tugtakín, hermano de Saladino, que cumple con el precepto de la peregrinación en medio de un cortejo fastuoso, rebosante de riqueza y de poder militar. Los habitantes de la ciudad permanecen maravillados contemplando el colorido espectáculo de los desfiles de los soldados armados del príncipe.

Ibn Yubayr, gran observador, no podía dejar de mencionar el día en que la Gran Mezquita se dedica en exclusiva a las mujeres. Afirma que generalmente las mujeres tienen que mantenerse apartadas de los ritos, pero en esta ocasión se adueñan del espacio religioso y todas las mujeres de La Meca acuden al lugar santo sin excepción.

Para lo viajeros medievales también tiene interés destacar en qué clase de lugar se encuentra emplazada la ciudad y todos ellos resaltan lo abrupto del terreno, las colinas que rodean la ciudad y el estrecho valle en el que está situado el núcleo urbano. Para Ibn Yubayr resulta milagroso que un lugar tan angosto pueda dar acogida a la gran afluencia de peregrinos en su época. No olvidan tampoco las impresionantes tormentas que afectan a la zona y que ya describían en sus poemas los poetas preislámicos.

\section{Imágenes de La Meca en dos novelas de R. Alem: Játim ${ }^{1}$ y Sidi Wahdana}

En lo que respecta a la obra de R. Alem, hay una clara separación entre las novelas que publica antes del año 2005, y las dos últimas obras, Sitr (Ocultamiento) (2005) y Tawq al-Hamam (El collar de la paloma) (2010). Esta última ha conseguido en 2011 el prestigioso premio Booker de la novela árabe.

Las imágenes de la primera época se pueden situar temporalmente en una ciudad de finales del siglo XIX o comienzos del siglo XX -como hace $\mathrm{N}$. Mahfuz al desarrollar el mundo de la hara (barrio, conjunto de callejas) en parte de su obra-, anterior a los cambios arquitectónicos que ha acarreado la introducción del automóvil en la vida de las ciudades en general ( $v i d$. Suleiman Shinaq 2001: 27). Se encuentran, por consiguiente, muy próximas a las de los viajeros medievales; con una diferencia digna de mención, y es

${ }^{1}$ Véanse más datos sobre la autora y la novela mencionada en Nuin (2008:127139). 
que los viajeros eran personas ajenas al medio que visitaban, mientras que R. Alem, que nació en la ciudad de La Meca a finales de la década de los sesenta, es una persona que conoce la ciudad en profundidad. Su padre había estado encargado de la administración del agua del pozo de Zemzem, cargo que se heredaba dentro de la misma familia desde la Edad Media.

El recurso a este pasado difuso, con pocas referencias históricas concretas, puede deberse, como en el caso de N. Mahfuz, a un deseo consciente de moverse en un terreno irreal dotado de una fuerte carga simbólica, que le permite a la autora disponer de un margen mayor de libertad por el que lucha a lo largo de su trayectoria denodadamente. Así ha esquivado hasta el momento la férrea censura.

Por otro lado, las imágenes que ofrece R. Alem, impregnadas de un profundo amor por la ciudad, ofrecen aspectos de la misma que han cambiado o están a punto de desaparecer para siempre, como las características arquitectónicas tan específicas de las casas mecanas del siguiente párrafo:

En uno de los innumerables meandros de la callejuela, interrumpida por escalones desgastados, se alzaba la casa, la morada de Nasib. Todos los lugares que daban al oeste de La Meca confluían en la cima de aquella casa, en la montaña de Hindi, que se asentaba en el corazón de la ciudad. Competía con la fortaleza turca en ocultar los soles de La Meca y en la observación de las estrellas. Ninguno de los que alcanzaban la casa podía evitar alzar los ojos hasta sus dependencias superiores, que parecían invadir con sus ejércitos de piedra el horizonte. Las miradas coincidían en considerarla como la más elevada de las casas de la montaña o incluso de toda La Meca, si contamos la base montañosa que la proyectaba hacia lo alto. Por ello, era objeto de curiosidad para las gentes de la montaña y para los curiosos del resto de los barrios. (Alem 2007: 9)

La autora destaca también el abrupto y árido suelo volcánico de la región de La Meca, algo que llama la atención de todos, sean originarios del lugar o foráneos, que se impone a la ciudad y a sus habitantes, obligados a sortear colinas o a edificar sus casas en altura, para obtener lo mejor de la superficie, aprovechando al máximo lo que el escarpado terreno ofrece.

Por otro lado el urbanismo de la ciudad santa se perfila en torno a un centro neurálgico, que es la Gran Mezquita, que alberga en su interior la construcción cúbica de la Caaba. Este edificio, construido en distintas etapas, es el centro de la ciudad, punto central hacia el que se dirigen las oraciones de los musulmanes del mundo. Dice a este respecto R. Alem cuando trata esta cuestión: 
Cuando abandonó el círculo del jeque Mastur, recorrió el camino a la Gran Mezquita. Se detuvo de pie en medio del patio, frente a la cúpula del pozo de Zemzem. De espaldas al pozo, la inundó el verdor de la cúpula. Permaneció frente a la negrura de la cobertura de la Caaba, que estaba impregnada de versículos coránicos. Empezó a reunir palabras y a memorizarlas para su laúd. Durante horas, permaneció inmóvil con su corazón en el patio de la circunvalación. Lo que se dibujaba ante ella era como si lo viera por vez primera. El movimiento entrelazado de los cuerpos que daban la vuelta a la Caaba. El movimiento de los cuerpos que entraban en la Gran Mezquita por primera vez con precaución. El movimiento de las puertas entornadas los ayudaba a deslizarse al interior con el movimiento de los cuatro puntos cardinales. Los cuerpos se unían al círculo que daba vueltas, y cuando avanzaban con miedo al mismo borde del círculo, un cuerpo delgado vestido de blanco se les acercaba y les decía en el interior:

-¿Haces la circunvalación, peregrino? (Alem 2007: 226)

Recientemente y debido al acceso a nuevas tecnologías, se ha producido un interesante fenómeno, y es que se ha descubierto que la mayoría de las antiguas mezquitas medievales de la ciudad tienen las paredes de la qibla (muro hacia el que se dirige la oración) mal orientadas. Ha habido que reorientar la dirección de los orantes en estos edificios, cuyos errores de orientación sólo se pueden achacar a lo escarpado del terreno.

También menciona la autora las terribles y cíclicas riadas que arrasan la ciudad cada poco tiempo llevándose por delante bienes, animales y vidas humanas, como se puede comprobar en el párrafo siguiente:

De pronto, reventó de agua el suelo de la montaña. Como de costumbre, las lluvias en aquel lugar sagrado no descendían gota a gota, sino que se derrumbaban como un rebaño salvaje que corriera en estampida hacia la Gran Mezquita. No caía el agua del cielo en aquella montaña que se adentraba en lo desconocido, sino que salía de debajo de cada piedra saltando en todas las direcciones, removiendo el círculo de lo prohibido para desaparecer después. Las casas de la montaña encontraban alegría en la lluvia incluso cuando causaba la muerte. Los corazones permanecían suspendidos de las celosías y las dependencias superiores con terrazas que quedaban desiertas para que el agua no arrastrara a ninguna de sus gentes, fuese vagabundo o amante. La lluvia torrencial tenía un recuerdo en cada torrentera que atraía los corazones dejando en su lugar alguna de sus historias. (Alem 2007: 31-32)

Es una situación que relatan las casidas preislámicas, los viajeros medievales y los noticiarios de la actualidad, sin que se haya logrado hallar ningún remedio eficaz para evitar estas calamidades cíclicas. 
Sobre la vida social de la ciudad santa, R. Alem hace el siguiente relato:

En el patio se unieron al repostero más famoso de La Meca. Allí el ritmo de la casa se volvía frenético. Todas las cosas se movían a una velocidad vertiginosa, precedidas por los dulces aromas de los animales asados, el del cocido y el del arroz mezclado con leche y manteca, muy sencillo, sin ningún aditivo excepto el mero sabor de la carne. Las más hermosas noches de tertulia se realizaban con la sencillez y dulzura de aquel arroz. Las bandejas pasaban a las casas de los vecinos. Un buen banquete no debía tener límites, pues los banquetes que se daban en la casa de Dios tenían la finalidad de prestar socorro. Alcanzaban las casas vecinas y concernían a todos sus habitantes, antes que a los invitados. Aquellos aromas debían perseguir a las gentes y entrar en cada casa a su manera. El banquete que no se extendía no decía nada bueno de quien lo había patrocinado. (Alem 2007: 30-31)

Cuando se intenta hacer una aproximación al ambiente de la ciudad, hay que tener presente el carácter cosmopolita de La Meca, pues desde la Edad Media ha albergado a gentes procedentes del continente africano y del asiático. Se trata de personas que poseen culturas y lenguas distintas, que sólo cuentan con un factor de cohesión, la religión.

En muchas ocasiones, las gentes con menos recursos económicos se refugiaban en La Meca huyendo de la extrema pobreza de sus lugares de origen, lo que ha favorecido el surgimiento de zonas urbanas ocupadas por población marginal causante de numerosos problemas, tanto en el pasado como en el presente. Dice al respecto la autora lo siguiente:

Su cuerpo era extremadamente consciente de lo que pasaba detrás de ella, como si estuviera caminando dentro de la zona prohibida. A sus espaldas se extendían barrancos de mala fama con chozas de cinc y cercados de madera que acogían a verdaderas multitudes de inmigrantes pobres. Esta era la zona del infierno, un lugar opuesto al otro costado de la montaña de Hindi, ocupado por las gentes acomodadas. La línea divisoria entre las dos zonas estaba ocupada por la pequeña mezquita abandonada. Hacía tiempo que no corría el agua por las dependencias de la mezquita. Y, cuando la gente observaba que había humedad en las pilas de las abluciones, decía que eran los ángeles quienes habían descendido una vez al año para habitar la mezquita y que no se arruinara el límite divisorio entre los dos mundos que se extendían a derecha e izquierda. (Alem 2007: 6869)

La autora no duda en hacerse eco de un hadiz (dicho atribuido al Profeta), según el cual el agua del pozo de Zemzem puede ser bebida para saciar la sed y como alimento. R. Alem menciona a los 
más pobres de entre los pobres, gentes procedentes de lugares recónditos de África y Asia, que se alimentan de pan enmohecido remojado en el agua salobre de este pozo ( $v i d$. Alem 1998: 95).

Además, alrededor de La Meca hay una serie de lugares de devoción (vid. Alem 1998: 72), que en la actualidad se encuentran englobados en el conjunto de la ciudad moderna. Ello hace que La Meca de hoy en día sea una ciudad muy extendida, que encierra en su interior zonas totalmente despobladas. Por ello es imprescindible el uso del automóvil en los desplazamientos en la ciudad.

\section{Imágenes recientes de La Meca en Tawq al-Hamam}

La vinculación de la ciudad a uno de los cinco pilares del islam, la peregrinación, la ha dotado de unas características especiales que han concluido en la radical transformación de la ciudad en la actualidad, donde se da un alto grado de especulación urbanística, enormes cantidades de dinero obtenidas de la peregrinación y un afán de destruir y construir en el que predominan enormes edificios de gusto dudoso que acosan por todos los lados a la Gran Mezquita. Todo se enfoca hacia el albergue de peregrinos, con lo que la construcción de hoteles progresivamente más caros es la línea dominante en el desarrollo de las nuevas edificaciones de la ciudad.

Poco a poco han ido desapareciendo las edificaciones tradicionales que rodeaban el espacio anexo a la Gran Mezquita para dar paso a hoteles modernos que ofrecen como máximo valor vistas "incomparables" al lugar religioso por excelencia, el patio de la Gran Mezquita.

En su última novela, Tawq al-Hamam (El collar de la paloma), R. Alem se plantea una apuesta bastante arriesgada: realizar una valiente aproximación a su ciudad natal, La Meca, en la actualidad, a la que define, destacando su carácter cosmopolita, con las siguientes palabras: "La Meca es una paloma cuyo cuello está rodeado por todos los tipos imaginables del espectro humano" (Alem 2011: 25).

Esta obra se ha dispuesto como una sucesión de piezas que encajan a la manera de un puzzle. En la parte antigua de la ciudad ha aparecido el cadáver de una mujer desconocida, y el inspector de la policía, Sr. Náser, efectúa una serie de pesquisas en los distintos barrios, que permiten al lector adentrarse en la ciudad actual y sus problemas. El personaje que inicia el relato es el propio callejón donde ha aparecido el cadáver, el callejón de Abú al-Ruús, al que la autora da voz y que sirve para dar cohesión a la historia. Por ello se puede afirmar que el lugar es muy importante en esta obra, aunque el interés por los distintos personajes que aparecen en la misma es lo primordial.

Por otro lado, la autora no evita tratar algunas cuestiones específicas de la sociedad saudí, como son los comportamientos paranoicos de algunos personajes, a los que se ven abocados por la 
presión social del grupo y la segregación de sexos, especialmente en el callejón en que viven. También destaca la forma tan peculiar de llevar a cabo la ayuda social para las familias pobres que viven en dicho callejón, como se puede observar en el siguiente párrafo:

Al atardecer un elegante Cadillac negro obstruía la entrada de Abú alRuús, pues se iba a examinar la situación social de las familias del callejón. Aquellas casas desvencijadas se rebelaron para resaltar su pobreza y así llamar la atención. Se apeó el conductor y lo siguió una mujer recubierta de negro desde la cima de la cabeza hasta los pies, con sus medias tupidas y los guantes hasta los antebrazos. Caminaron a lo largo de la calle mientras los observaban los ojos de la gente desde detrás de las ventanas. (Alem 2011: 204)

No obstante, las obras de R. Alem no admiten nunca una lectura simplista y apresurada, pues siempre encierran en su interior una fuerte carga simbólica. Por ello, el cadáver de la mujer bien podría representar a la propia ciudad, que soporta con paciencia todo tipo de violencias. El relato se abre con la siguiente reflexión:

El edificio que está marcado con el signo de la equis en rojo está preparado para desaparecer antes de convertirse en un lugar para albergar esos seres extraños que tienen cuatro ruedas y que parece que se van a adueñar de La Meca, según figura en el hadiz sobre los Signos de la Hora: "Se arrojará el oro en los caminos". Cuando éramos pequeños, leíamos aquello y nos parecía muy extraño. Pero, considerando el precio elevadísimo de los coches, cuyo número supera al de los seres humanos en las calles de La Meca, podemos afirmar que hay oro tirado por los suelos. Las montañas se desvanecen tragándose las antiguas edificaciones, y con ellas, la casa de mi abuelo que se elevaba sobre la cima conocida por los Balcones de la Gran Mezquita, en el barrio de Estambul de La Meca. Todo ese pasado ingenuo se ha desvanecido ahora, sin que tenga más presencia que en este libro. (Alem 2011: 1)

Se ha horadado el monte Hind para facilitar las vías de entrada y salida de la ciudad y se han construido diversos túneles, con lo que el carácter de la ciudad se ha transformado radicalmente, orientándose a facilitar la peregrinación de gente con recursos económicos notables. Se ha cambiado el nombre de algunas calles, como la calle de Abú al-Ruús, donde se desarrolla la novela por el nombre de Darb al-Nur, "para embellecer la historia", como afirma la autora (Alem 2011: 120).

Como ha sucedido en otras ciudades, por ejemplo El Cairo, el patrimonio artístico del centro de la ciudad ha sido objeto de especulaciones de todo tipo y también ha sido y es víctima del expolio; el precio del suelo ha pasado en poco tiempo de tres mil riales el metro a cien mil, se ha construido sin control, y la armonía 
que existía con anterioridad en lo que respecta al tamaño y diseño de los edificios se ha perdido sin posibilidad de remisión.

En esta obra se pueden detectar numerosos pasajes dedicados a destacar el feísmo que parece dominar las nuevas edificaciones de la ciudad, como el bloque de apartamentos donde vive desde hace veinte años el inspector Náser. Son construcciones de mala calidad, que enseguida se llenan de grietas, como los edificios de apartamentos de alquiler que se amontonan al pie del monte Hind. Uno de los personajes reflexiona sobre la imposibilidad de que estos edificios resistan el paso del tiempo.

A pesar de todo, estas son imágenes que podrían hacerse extensivas a los barrios nuevos de otras ciudades, como El Cairo, Argel, Casablanca, Damasco, etc.

No obstante, el afán destructor y ampliador del espacio original no ha afectado solamente al entorno exterior, sino también al interior, lo que ofrece más dificultades de aceptación desde un estricto punto de vista religioso. La enorme ampliación de la Gran Mezquita realizada en el siglo XX ha acabado no sólo con los alrededores del templo, sino también con algunos elementos "menores", pero no menos importantes, del interior. El pozo de Zemzem, del que se extraía el agua con un cubo, también se ha reformado. Se ha ahondado para buscar un caudal mayor, se han instalado grifos, y el agua ha dejado de tener su aspecto tradicional, con su sabor salobre y un poco de espuma, para convertirse en algo insípido.

Todo ello lo subraya en su obra la autora, que no pretende en ningún momento escribir una obra de denuncia, sino simplemente relatar unos hechos objetivamente.

\section{Imágenes de otras ciudades saudíes: Medina, Riad, Yidda}

Sobre Medina, ciudad con una gran carga religiosa también, dotada de un ambiente muy tradicional y cuyo centro neurálgico es la mezquita en la que está enterrado el Profeta del islam, la autora dice lo siguiente:

Cuando salió de la Mezquita del Profeta, el alba ya asomaba a la ciudad, rozando apenas la calle de Ayyiniya, que sube desde la puerta de Salam. A ambos lados de la polvorienta calle, se alineaban las tiendas de ropa, oro y rosarios, a la espera de visitantes y peregrinos. Junto a las tiendas y a los dos costados de la puerta de Salam, se distribuían las africanas y las mujeres de Hiyaz con sus tenderetes. Había vendedoras de dátiles, de grasa para cocinar y de leche agria que atraían la atención con sus calabazas y sus fuentes en las que flotaba la espuma. Las vendedoras de tortas confiaban su suerte al perfume embriagador, una mezcla de semillas de hinojo y de neguilla que perforaba el olfato y atraía a los que venían de los pórticos. Sharra se inclinó hacia la vendedora de leche, que era una africana 
que sostenía a su hijo lactante atado a la espalda mientras se inclinaba para tomar la leche con una gran calabaza de los recipientes de barro cocido. A su alrededor se congregaba el círculo de clientes que venían de la Mezquita. (Alem 2007: 18-19)

Raja Alem, que está muy lejos de poder ser calificada como una escritora realista, describe el trazado actual de la ciudad de Riad como el cuerpo de una gacela desmembrada, con unas extremidades muy largas y espacios urbanos ocupados por el desierto.

Para recorrer las largas distancias, no queda más remedio que recurrir al automóvil, y los personajes de Sitr (Ocultamiento) (2005) ocupan largos pasajes de la novela mientras se desplazan de un lugar a otro en este medio. Todo ello contrasta con el ritmo temporal que se muestra en los desplazamientos en camello, que aparecen en las obras anteriores y que la autora no duda en resaltar por su contraste.

La novelista ofrece sobre Riad las siguientes apreciaciones, en las que de forma indirecta se posiciona contra los abusos arquitectónicos de nuestro tiempo:

Tomó las maletas y las colocó cuidadosamente en el asiento trasero. La hizo sentarse a su lado mientras cruzaban las calles de Riad. Riad es una ciudad que no ha terminado de convertirse en realidad; se halla a medio camino entre la arena del desierto y el aduar, entre el ser humano y la fiera. Su cuerpo se compone de los miembros de una gacela que de tanto correr se han diseminado en enormes extensiones de desierto. Una gacela que ha galopado durante siete décadas y que, al darse la vuelta para recoger sus miembros, ha hallado una ciudad perseguida por cazadores que han construido elevadas murallas en su camino y en su cuerpo. De tal manera que ya no puede lanzar una mirada fugaz para armonizar sus miembros, el antimonio de sus ojos y la feminidad de su huida.

Hay una feminidad oculta en Riad, de la que el visitante sólo puede percibir un severo recuerdo que oscila entre la arena y la fiera. Es una ciudad cuerpo que ni da la bienvenida ni permite que en ella se albergue el que va de paso.

Pero el cuerpo de Taful es una gacela errante que lee los secretos de la ciudad en su arena. La torre Faysaliya observa la ciudad, y junto a ella se alza la torre del Reino; son éstas dos torres distraídas en un tiempo que sólo permite que las torres se levanten corroídas por el acero y el cristal, amasadas en una harina pastelera de proporciones gigantescas. (Alem 2005: 42-43)

Parece ser que la ciudad de Yidda, que se encuentra más alejada de connotaciones religiosas y de extremismos, ofrece, como en el caso de Riad, una aproximación más moderna en lo que respecta a edificaciones y al ambiente social de la ciudad. Por todo ello la autora presenta las siguientes observaciones sobre la ciudad de Yidda: 
A su regreso de Londres, Mariam era más consciente de la feminidad de la ciudad, agobiada de pasión. Ninguna ciudad era comparable a la Novia del Mar, con sus arrebatadores edificios y sus villas de diseño incomparable. Ninguna edificación repetía el trazado de la siguiente, no había nada que imitara la magia de su vecina. La clase media se había apresurado a tomar posesión de su mar para ocultarlo a la vista de la gente corriente. Los niños afganos que pedían limosna junto a los semáforos se bañaban con todas sus ropas como si fueran muñecos colgados en los escaparates prohibidos de la cornisa. (Alem 2005: 36)

En otro pasaje de la misma novela, la autora reitera su visión de la ciudad, a la que considera como una presencia femenina, revestida de elementos procedentes del desierto que la han tomado por sorpresa, sin su consentimiento expreso, como se puede observar en el párrafo extraído a continuación:

Yidda posee un rostro que se oculta detrás del hecho de ser la Novia del Mar, una máscara que se muestra para domeñar el rostro femenino de la ciudad, mientras se esconde el rostro masculino con su característica mercuriana que propicia la huida. Es una máscara plana sin señales históricas ni olores antiguos del Hiyaz, portadora del viento del desierto y del extremismo de sus tribus, que ha revestido a la ciudad a su pesar. (Alem 2005: 92-93)

\section{Conclusión}

Las imágenes literarias de ciudades saudíes que ofrece R. Alem en sus últimas novelas oscilan entre la relativa modernidad de Yidda y Riad y el enorme peso de la tradición en Medina y La Meca. Y, sin duda, es esta última ciudad la que ocupa el centro de su interés literario.

Además, la obra de R. Alem, aunque tiene aspectos que la aproximan al realismo mágico, si por ello se entiende la narrativa producida en el Tercer Mundo, estaría mejor situada en el terreno de la definición de la propia identidad ${ }^{2}$, algo que está más próximo a las intenciones de la escritora. Hay que señalar, una vez más, que son las suyas obras escritas en árabe y que están destinadas a lectores árabes cultos, tanto saudíes como de otros países árabes. Estos últimos lectores sienten gran curiosidad por lo que sucede en la sociedad saudí, hermética también para ellos.

$\mathrm{Y}$, con todo, las novelas de R. Alem, a pesar de sus fuertes vínculos con el lugar, no son novelas de corte localista, pues están muy conectadas con un mundo contemporáneo transfronterizo en todos sus aspectos, especialmente las dos últimas, Sitr y Tawq alHamam.

\footnotetext{
${ }^{2}$ Véase a este respecto el artículo de Erna von der Walde (1998).
} 
Por todo ello, tal vez las coordenadas para situar a la autora consistan en la búsqueda y definición de la propia identidad, por un lado, y en el mundo de la globalización, por otro.

\section{Bibliografía}

ALEM, Raja (1998): Sidi Wahdana (Mi señor Wahdana). Beirut / Casablanca: Al-Markaz al-Zaqafi al-Arabi.

- (2005): Sitr (Ocultación). Beirut / Casablanca: Al-Markaz al-Zaqafi alArabi.

- (2007): Játim. Traducción de Milagros Nuin. Madrid: Huerga y Fierro editores.

- (2011): Tawq al-Hamam (El collar de la paloma). Beirut: Al-Markaz alZaqafi al-Arabi.

IBN YUBAYR (1988): A través del Oriente. El siglo XII ante los ojos. Rihla. Barcelona: Ediciones del Serbal.

NASIR-I JUSRAW e IBN CHUBAYR (1999): Dos viajeros musulmanes. Barcelona: Círculo de Lectores.

NUIN, Milagros (2008): "Una novela de Arabia Saudí: Játim de la autora Raja Alem". Anaquel de Estudios Árabes, vol. 19, pp. 127-139.

SULEIMAN SHINAQ, Mazen (2001): La ciudad musulmana y la influencia del urbanismo occidental en su conformación. Madrid: Cuadernos de investigación urbanística, núm. 33.

WALDE, Erna von der (1998). "Realismo mágico y poscolonialismo: construcciones del otro desde la otredad", en Santiago Castro-Gómez y Eduardo Mendieta (eds.), Teorías sin disciplina. México: Miguel Ángel Porrúa. 